\title{
PRELIMINARY SELECTION CRITERIA FOR THE YUCCA MOUNTAIN PROJECT WASTE PACKAGE CONTAINER MATERIAL
}

\author{
W.G. HALSEY
}

Publication date: February 1991

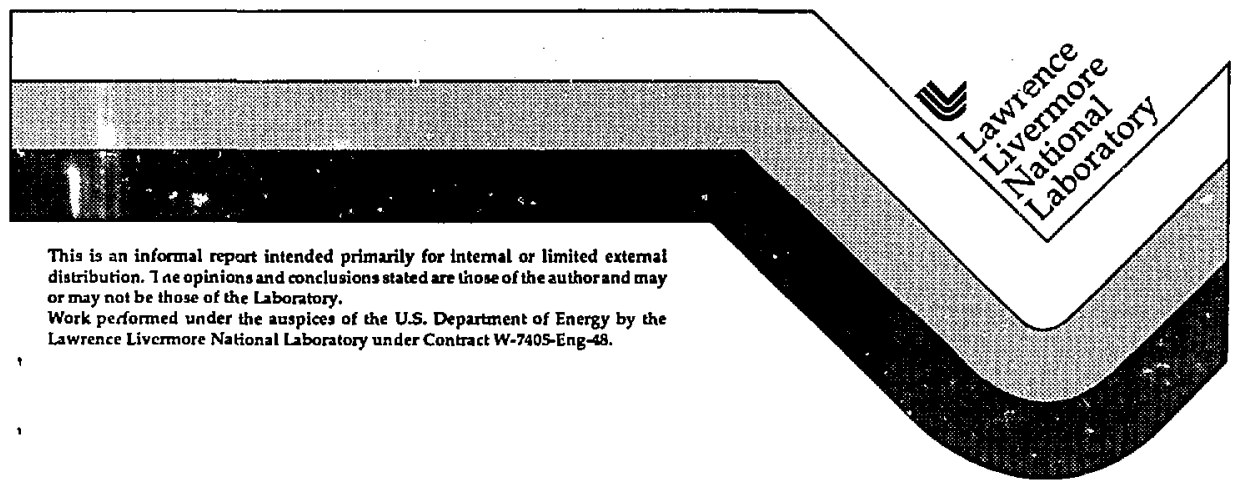


This document was prefared as an account of worin sponsored by an azency of the United States Government. Neither the United States Government nor the University of Califomiz nor any of their employsts, makes any warranty, express or implied, or assumes ary legal liability or responsibility for the accuracy, completeness, or usefulness of any intormalion, apparatus, product, or process disclosed, ne represents that its use would nol infringe privalely owned righls. Refe-ence herein to any spectfic commercial products, pracess, or service by trade name, trademark, manufastures, or otherwise, does not necessapily constitute or imply itg endorsement. recommendation, or favoring by the United States Government or the University of California. The views and opinions of authors expressed herein do not necessarily state ar reflect those of the United States Government of the University of Californis, and shalf not be used for adverlising of produst endarsement purposes.

Tilis repart has been repraduced

direstly from the best available sopy.

Avalluble 10 DOE and DOE contractors trom the

Otflex of Sclentific and Teehnical tniermation

P.O Hox ol OAk Ridge, TN 37831

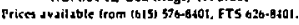

Avsluble ta ins public fram the

Nationd I Technixal Informstion Strrice

U.S. Depariment of Commerce

5265 Port Rayel RA.

Springfield, va 2110

Price

Code

A.01

\section{Fupercopy Prices}

$\begin{array}{lr}\text { A02 } & 1-10 \\ \text { A03 } & 11-50 \\ \text { A09 } & 51-75 \\ \text { A05 } & 76-100 \\ \text { A06 } & 101-125 \\ \text { A07 } & 126-150 \\ \text { A08 } & 151-175 \\ \text { A09 } & 176-200 \\ \text { A10 } & 201-225 \\ \text { A11 } & 226-250 \\ \text { A12 } & 251-275 \\ \text { A13 } & 276-300 \\ \text { A14 } & 301-325 \\ \text { A15 } & 326-350 \\ \text { A16 } & 351-375 \\ \text { A17 } & 376-400 \\ \text { A18 } & +01-425 \\ \text { A19 } & +26-450 \\ \text { A20 } & +51-475 \\ \text { A21 } & +176-500 \\ \text { A22 } & 501-525 \\ \text { A23 } & 526-550 \\ \text { A24 } & 551-575 \\ \text { A25 } & 576-600 \\ \text { A99 } & 601 \& \text { \& }\end{array}$

Page

Range

Microfiche 
UCRL-ID--104552

LE91 009717

\author{
Preliminary Selection Criteria \\ for the Yucca Mountain Project \\ Waste Package Container Material
}

William G. Halsey

Lawrence Livermore National Laboratory

January, 1991

\title{
DISCLAIMER
}

This report was prepared as an account of work sponsored by an agency of the United States Government. Neither the United States Governmeat nor any agency thereof, no: any of their emplcyos, makes any warranty, express or implied, or assumes any legal liability or responsibility for the aecuracy, completeness, or usefulness of any information, apparatus, product, or process disclosed, or represents that its use would not infringe privately owned rights. Relerence herein to any specific commercial product, process, or service by wade name, irademark. manufacturef, of otherwise does not necessarily constitute or imply its endorsement, recommendation, of favoring by the United States Gavernment of any agency thereof. The views and opinions of authors expressed herein do not necessarily stale or reflecl those of the Uniled States Government of any agency thereof. 
The Department of Energy's Yucca Mountain Project (YMP) is evaluating a site at yucca Mountain in Nevada for construction of a geologic repository for the storage of high-level nuclear waste. Lawrence Livermore National Laboratory's (LLNL) Nuclear Waste Management Project (NWMP) has the responsibility for design, testing, and performance analysis of the waste packages. The design is performed in an iterative manner in three sequential phases (conceptual design, advanced conceptual design, and license application design). An important input to the start of the advanced conceptual design is the selection of the material for the waste containers. The container material is referred to as the 'metal barrier' portion of the waste package, and is the responsibility of the Metal Barrier selection and Testing Task at LLNL. The selection will consist of several steps. First, preliminary, material-independent selection criteria will be established based on the performance goals for the container. Second, a variety of engineering materials will be evaluated against these criteria in a screening process to identify candidate materials. Third, information will be obtained on the performance of the candidate materials, and final selection criteria and quantitative weighting factors will be established based on the waste package design requirements. Finally, the candidate materials will be ranked against these criteria to determine whether they meet the mandated performance requirements, and to provide a comparative score to choose the material for advanced conceptual design activities. This document sets forth the preliminary container material selection criteria to be used in screening candidate materials.

Relevant background information which serves as input for the selection process includes: the performance requirements of the container (interpreted from pertinent federal regulations), possible container designs (From the conceptual design phase), and potential service conditions for the container (from preliminary environment studies of Yucca Mountain).

Performance requirements for waste packages in the repository are provided in NRC regulation 10 CFR Part 60 [1] as "substantially complete containment" for a period of time yet to be determined, bit between 300 and 1000 years, and a "controlled release period: of up to 10,000 years. The performance goal for the metal barrier is specified by the DoE in the YMP Site characterization Plan [2] as a maximum fractional container failure rate for different time periods after repository closure. While it is expected that most of the containers will not be exposed to liguid water, provision is made for bath "wet" and "dry" containers. These performance goals have changed in detail as the interpretation of substantially complete containment has been refined. Allowed container failure rates between $0.0001 /$ year and $0.01 /$ year are typical of the performance goals proposed. For a full repository this translates into a few to a few hundred failures in any year. In addition, the container must be compatible with the waste forms, must not compromise the performance of other repository components, and must provide for transportation, handing, retrievability, and unique identification. 
While the container design is not yet final, a typical conceptual design is a closed metal cylinder about $66 \mathrm{~cm}$ in diameter and $300-500 \mathrm{~cm}$ long. The container would be made from a corrosion resistant material about one centimeter thick. A variety of fabrication options are under consideration, such as rolled and welded plate, cast, or extruded. The bottom might be integral or forged and welded. Any fabrication joints except the final closure can be readily annealed to relieve stress. The final closure has been identified as a feature that could potentially limit long-term container performance and should receive special attention.

The waste package will be placed in a mined geologic environment which is about 1000 feet below ground and about 1000 feet above the water table in a stratum of welded, devitrified, tuff rock. This location results in a relatively dry condition without hydrostatic or significant lithostatic loads. Thus, the stresses in service are limited to residual stresses, such as residual stress in the closure weld if the container is welded, and the static load from tine weight of the container and waste. Additional transient and impact loads will occur during transportation, handling, and possible retrieval. The container must be able to survive a small drop or handling impact without loss of integrity.

The container will undergo a low temperatuze but very long-term thermal cycle which may allow metallurgical changes in the material. Decay heat from the spent fuel will raise the temperature of the container surface to as much as $250 \mathrm{c}$ after the repository is closed. Over a period of hundreds of years, the temperature wili slowly drop as the waste decays. The temperature of some containers may still be over $100 \mathrm{C}$ after 1,000 years, while others may cool more rapidly. The effect of this long-term thermal aging on the weld metal and heat affected zore of possible closure welds is of particular interest.

The corrosion environment will also change with time. When the containers are hot, there can be no liquid water contact. The environment then will be a warm air-steam environment conducive to oxidation. When the temperature drops below the boiling point, the low water infiltration rate at Yucca Mountain is expected to limit exposure to water. Condensation is unlikely because the container surface will be the hottest surface in the repository airspace. However, it is considered possible that dripping, or even flow of water onto some of the containers may occur. This would bring about an aqueous phase environment conducive to dissolution, pitting and crevice corrosion, and environmentally assisted cracking. The grourdwater associated with the repository site is near neutral in $\mathrm{pH}$, oxygenated, and fairly low in ionic content. Mechanisms have been proposed by which the solutes in the groundwater could become concentrated and result in a more aggressive environment.

The gamma radiation from the waste decay will produce radiolytic alterations in the local environment in the early time period. This will. include generation of ozone, nitrogen oxides, nitric acid, and ammonia from irradiation of moist air and hydrogen peroxide from irradiation of liquid water. Radiolytic effects will be smaller in the later years when. the temperatures have dropped below boiling because of the associated decrease in the radiation dose rate. 
It can be seen that a variety of service condicions, some expected or nominal, and some potential or bounding, may be encountered by the container material. Preliminary selection criteria for the advanced conceptual design container material will be discussed, taking account of the performance requirements, conceptual design, and service conditions discussed above.

The criteria fall into two general categories: those related to the performance of the container material in the repository, and those non-performance-related topics dealing with cost and practicability of fabricating a container from the material. Within these categories the criteria are divided into seven topical areas and given relative weighting factors:

Weighting Factor

14
30
16
10
20
5
5

30

16

10

5
MATERIAL PERFORMANCE

A) Mechanical performance

B) Chemical performance

C) Predictability of performance

D) Compatibility with other materials FABRICABILITY, COST, AND OTHER CONSIDERATIONS

E) Fabricability

F) Cost

G) Previous experience with the material

Within each of the seven topical areas there are several specific sub-topics, each of which receives a share of the topic area weighting. At this level the criteria are material-independent and are equaliy applicable to any candidate container material. It should be noted that each of the performance criteria must be considered for a variety of combinations of material conditions and environments (including irradiation). The "worst-case" combination for each material and criterion is the one used for evaluation. If the "worst-case" for a criterion is not readily identifiable it may be necessary to evaluate several or all combinations of material condition and environment. The combinations of conditions and environments are the following:

Base material/Closure material

As fabricated/Aged condition

Nominal environment/Potential environment

Note also that many of the criteria are interrelated and may overlap in some areas. The material-independent selection criteria topic areas, sub-topics, and weighting factors are shown below: 
Weighting

Factor

\section{PART A: MATERIAL PERFORMANCE}

Will the material meet the performance allocated to the container in achieving the containnent objectives (substantially complete containment under anticipated processes and events occurring in the repository)? can the performance of the material under repository conditions be adequately predicted? Will the container material interact. favorably with other components?

A) Mechanical performance
1) Strength
2) Toughness
3) Phase stability

B) Chemical performance
1) Resistance to general corrosion (oxidation, aqueous corrosion).

2) Resistance to pitting, crevice, or other localized attack).

3) Resistance to environmentally accelerated cracking (stress corrosion cracking and $\mathrm{H}$ enbrittlement).

4) Resistance to microbiologically influenced corrosion.

c) Predictability of performance

1) Existence of predictive methods to explain and predict degradation phenomena and to extrapolate existing performance data to repository time scales and conditions, or ability to develop such methods.

2) Existence of long-term performance data.

3) Ability to generate required data.

4) Relative licensability.

D) Compatibility with other materials

1) Inceractions with waste form.
2) Interactions with the package environment and borehole liner.

Part B: FABRICABILITY, COST, AND OTHER CONSIDERATIONS

can a container be made of this material? Is it practicable?

E) Fabricability
1) Fabricability of container body.
2) Ability to close and seal the container.
3) Inspectability of closure.
4) Post-closure damage tolerance.

F) Cost

1) As-fabricated container costs.

2) Associated exceptional repository handling costs.

3) Strategic availability of material.

G) Previous experience with the material.

3) Existing engineerlng standards for the material. 
At the next level of detail, the criteria are described by scalable parameters that can be quantified. This quantification may be either objective (such as relating a physical parameter to a score) or subjective (by professional judgement). In some cases a topic is described by only one parameter, for example Al) strength is described by the parameter "yield strength" :

\section{A) Mechanical Performance \\ A1) Strength \\ Weighting Factor: 6 \\ Parameter: Yield strength}

In other cases several parameters may be used to describe a topic, for example E2) Closeability of container is divided into E2a) General process consicerations and E2b) External process considerations:

E) Fabricability

E2) Closeability of container.

Weighting Factor: 5

E2a) General process considerations Weighting Factor: 3

Parameter: Subjective opinion of closure processes

E2b) External process considerations. Weighting Factor: 2

Parameter: subjective opinion of external influences

While the criterion topic is material-independent, the scalable parameters, which describe the criteria, will vary with the material being evaluated, particularly in the performance topics. This is true because different materials have different properties and different susceptibilities to degradation. An example of this is found under the topic of localized corrosion, where one parameter is the likelihood that the repository enviroment contains an ionic species that is known to promote pitting attack in a concentration sufficient to cause a performance problem. Different types of metal are pitted by different ionic species. Therefore, the parameter would vary for different materials, but the intent of the criterion is the same, that is, to evaluate the degree to which pitting aitack is a performance-limiting problem.

It should be noted that these selectior criteria endeavor to condense a complicated set of interrelated phenomena and conditions into a sufficiently simple set of parameters to allow objective comparison of different materials. It is not intended to discuss in this document all of the details which must be considered during the selection. It is intended to provide the topic areas and quantitative framework for the selection. 
As described earlier, this selection process is being performed in the interim between the first and second phases of a three-phase iterative design process. The inputs to the selection are from the first, Conceptual Design (CD) phase, and the material selection itself is an input into the second, Advanced Conceptual Design (ACD) phase. Further material testing, container design and analysis, and repository environment determination will be performed during the ACD phase. After $A C D$ the desiç and material performance will be assessea for adequacy to allow confirmation or revision of the material selection prior to the start of the final, License Application Design [LAD] phase. A variety of. container design concepts will be considered as alternatives to the conceptual design before and during ACD. The final design concept will be developed during LAD. Detailed description of the container performance requirements can be found in the SCP [2]. Container material degradation is discussed in the Degradation Node surveys [3]. Program documents which describe the resilts of the $C D$ phase include results of material testirg found in UCID-21044 [4] and enginee:ing analyses of the CD container designs found in UCRL-53595 [5].

It is intended to have a two-part selecticn process. The first part is a "Pass/Fail" (P/F) to determine whether each candidate meets the minimum performance goals for the waste package, and whether it is a practicable material to use in this application. The second part is a "Quantitative Score" (QS) to determine a numerical value for each candidate, allowing the relative merit of each to be crmpared in order to select the "best" candidate. To support these goals, each parameter requires a passing score and a quantitative scale. In some cases, it is possible to correlate a measurable material parameter to the quantitative scale, and to identify a minimum or maximum passing value of that parameter. These passing scores should be values beyond which the material would not be acceptable for use. In other cases it is not possible to have such a closed set of parameter, scale, and passing score for one oi three reasons: 1) the parameter may not be fully quantifiable, 2) a quantitative pass/fail mark may not be identifiable, or 3 ) there may not be sufficient data available at the time of material selection to rigorously score a candidate material on the parameter. In these cases, a subjective judgement of acceptable/unacceptable must be used. The collective professional judgement of a number of knowledgeable persons will determine the Pass/Fail portion of such criteria. The pass/fail will be a determination of adequate/inadequate for each material on the given property rather than a minimum or maximum passing score for the quantifiable parameter associated with that property. Any opinion of inadequate must be supported by a written explanation and if agreed upon by a consensus of knowledgeable persons will disqualify that material from further consideration. 
With all of this included, an example parameter is Bl) Resistance to general corrosion:

Bi.) Resistance to general corrosion (oxidation, aqueous corrosion).

Weighting Factor: 8

Parameter: Time average oxidation rate (micrometers/year)

Passing score: 1.0 micrometer/year maximum

Score: $0 \ldots \ldots 1 \ldots \ldots 2 \ldots \ldots 3 \ldots \ldots 4 \ldots . \ldots 5 \ldots 6 \ldots . \ldots 7 \ldots . \ldots 9 \ldots 10$

Scale: $100.10 .0 \quad 1.0 \quad 0.1 \quad 0.01$

Units: micrometers/year

In presenting the criteria, additional commentary is often needed to explain the parameter or scale. In the example above, comments add that the averaged corrosion rate is the combined effects of vapor phase oxidation and aqueous phase dissolution for the expected temperature and environment as a function of time during the containment period. Thus, the oxidation rate in the early years, when the container is hottest and the radiation field is highest, might exceed one micrometer/year, but the maximum wall thinning expected over a 1000-year containment period would be 1000 micrometers. This one parameter then involves the effects of time, temperature, radiation, chemical environment, and material condition. As stated earlier, the performance criteria should be judged for the worst-case combination of:

Base material/closure material

As fabricated/Aged condition

Nominal environment/Potential environment

While it would seem consistent to have both a passing score and a quantitative scale for each criterion, in some cases it is appropriate to eliminate one or the other. Some topics do not really have a "passing score" below which the material is not usable. In these casas, only the quantitative score is established and the passing score is marked "NA" for "not applicable". An example of this is previous experience. There is really no minimum experience required, iut a material with many established applications and standards should be easier to license than one without. In other cases, there is a minimum requirement, but having more than that requirement does not really add to the usefulness of the material. An example of this is strength. The container must be strong enough to handle all anticipated loads with a reasonable safety factor, but beyond that, great sirength does little good. In these cases, the quantitative scale is omitted with an entry of NA. 
It should be noted that the topic areas were selected to answer the questions of required performance and practicability and are material-independent. The candidate materials have received considerable thought and examination prior to being included in the candidate 1 ist. Therefore, it should be expected that most of the candidates will pass all of the minimum score (or adequacy) tests, and will compete favorably or the quantitative score. Indeed, some criteria or entire topic areas may yield no differentiation between the candidates. These criteria are still included in the process to document that the candidates meet performance or practicability requirements.

In the following pages are presented the preliminary selection criteria with weighting factors, parameters, minimum scores, quantitative scales, and explanatory comments.

\section{References:}

1. "Disposal of High-Level Radioactive Wastes in Geologic Repositories, Technical Criteria," 10 CFR Part 60, Nuclear Regulatory Agency, Federal Register, Rules and Regulations, Vol. 48, No. 120 (Tuesday, June 21, 1983), pp. 28194-28229. HQ2.870302.3019

2. "Site Characterizatior Plan, Yucca Mountain Site, Nevada Research and Development Area", Nevada, U.s. Department of Energy, Office of Civilian Radioactive Waste Management, DOE/RW-0199 (December 1988). (Refer to sections 7.4 and 8.3 .5 .9 ). HQ0.881201.0002

3. D. B. Bullen, J. C. Farmer, G. E. Gdowski, R. D. Mocright, R. A. Vankonynenburg, and $H$. Weiss, survey of Degradation Modes of Candidate Materials for High-Level Radioactive-Waste Disposal Containers, 8 Volimes, Lawrence Livermore National Laboratory, Livermore, California, UCID-21362 (.988). NNA.891222.0305 through NNA.891222.031:

4. R. D. McCright, W. G. Halsey, R. A. Vankonynenburg, progress Report on the Results of Testing Advanced Conceptual Desiqn Metal Barrier Materials Under Relevant Environmental conditions for a Tuff Repository, Lawrence Livermore National Laboratory, Livermore, California, UCID-21044 (December 1987). NNa.871214.0013

5. W. C. O'Neal, D. W. Gregg, J. N. Hockman, E. W. Russell, and W. Stein, Preclosure Analysis of Conceptual Waste Package Designs for a Nuclear Waste Repository in Tuff, Lawrence Livermore National Laboratory, Livermore, California, UCRL-53595 (November 1984). NNA.891026.0013 
A) Mechanical Performance

Weighting Factor: 14

A1) Strength

Weighting Factor: 6

Parameter: Yield strength

Passing Score: Adequate/Inadequate (approximately $10 \mathrm{ksi}$ (69 MPa) minimum)

Score: Fars (5) / Fail (0)

Scale: NA

This assures adequate strength for static and handing loads. Absolute minimum values are not currertly available; however, typical conceftual design loads are about 1-3 ksi (7-21 MPa) (without safety factor). This criterion applies at the possible $250 \mathrm{C}$ service temperature and nust still be met after the long term aging of the material.

A2) Trighness

Weighting Factor: 6

Parameter: Plane-strain fracture toughness $\left(\mathrm{K}_{\mathrm{IG}_{\mathrm{g}}}\right)$

Passing Score: Adequate/Inadequate (approximately $50 \mathrm{ksi( \textrm {in } ) { } ^ { 1 / 2 }}$ $\left(55 \mathrm{MPa}\left(\mathrm{m}_{j} ;{ }^{1 / 2}\right)\right)$

Score: Pass (5) / Fail (0)

Scale: NA

This assures sufficient fracture toughness to withstand imvact loads during handling. Absolute minimum values are not currently available; however, typical enginejering applicatjons require approximately $50 \mathrm{ksi}$ (in) $1 / 2$ (55 $\mathrm{MPa}(\mathrm{m}) \mathrm{1/2}$ ). Fracture toughness can be inferred from measured stress intensity factor for fracture $K_{\text {If }}$ (or appropriate empirical correlations or elastic-pilastic $J$-integral method). Note that this criterion must be met by the final closure weld (if welded) and heat affected zone after a long term aging cycie.

A3) Phase stability

Weighting Factor: 2

Parameter: Relative metallurgical phase stability

Passing Score: Adequate/Inadequate Score: $0 \ldots \ldots 1 \ldots \ldots 2 \ldots \ldots 3 \ldots \ldots 4 \ldots \ldots 5 \ldots . \ldots 6 \ldots 7 \ldots 8 \ldots . \ldots 9 \ldots 10$ Scale: Bad Poor Moderate Fair Good Excell. Units: relative phase stability

Relative metallurgical stability of base metal and final closure weld (if welded) and heat affected zone during long term (1000 years) aging at moderate tenperatures (up to $250 \mathrm{C}$ ). 
Weighting Factor: 30

BI) Resistance, to general corrosion (oxidation, aqueous corrosion).

weighting Factor: 8

Parameter: Time average oxidation rate (micrometers/year)

passing score: 1.0 micrometer/year maximum

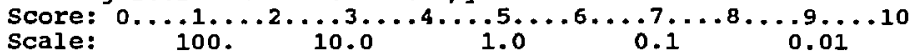

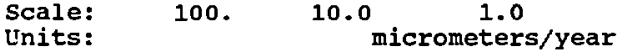

This is the average general corrosion rate (from oxidation ana acqueous corrosion phenomena) for the expected time, temperature, and environment for the containment period. The criterion is a wall thinning, or the sum of corrosion on the interior and exterior of the container. The passing score then allows for up to 1 millimeter of wastage from oxidation in 1000 years.

B2) Resistance to pitting, crevice, or other localized attack.

Weighting factor: 7

Parameter: Penetration rate

Passing score: 1.0 micrometer/year maximum

score: $0 \ldots \ldots 1 \ldots . \ldots 2 \ldots 3 \ldots .4 \ldots 5 \ldots \ldots 6 \ldots . \ldots 7 \ldots 8 \ldots 9 \ldots 10$

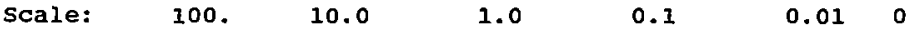

Units: micrometers/year

This is the projected average rate of penetration of localized corrosion phenomena during the first 1000 years under the expected metallurgical (including the aged material) and environmental conditions. This criterion applies to both the interior and exterior of the container. A material which does not allow initiation of localized corrosion in the expected environmental and service conditions can be given $a$ ' 0 ' penetration rate. The likelihood of localized corrosion includes consideration of topics such as the difference between the critical potential for pit initiation and the free corrosion potential, ionic concentrations expected, possible concentrating effects, thermal conditions, and quantity of water present, ali as functions of time. 
B3) Resistance to environmentally accelerated cracking EAC (stxess corrosion cracking and hydrogen embxittlement).

Weighting factor: 10

B3a) Threshold stress intensity for corrosion cracking

Weighting Factor: 2

Parameter: $\mathrm{K}_{\mathrm{I}} / \mathrm{K}_{\mathrm{Iscc}}$

Passing score: "

score: $0 \ldots \ldots 1 \ldots .2 \ldots . \ldots . \ldots 4 \ldots . .5 \ldots 6 \ldots .7 \ldots . \ldots .69 \ldots 10$

scale: 1.0

0.8

0.6

0.4

0.2

Units:

stress intensity/critical stress intensity

This is the ratio of expected stress intensj.ty $K_{T}$ (due to residual stresses, applied stresses, and internal flaws), to the critical stress intensity $\mathrm{K}_{\mathrm{Iscc}}$ for $\mathrm{SCC}$ under expected metallurgical (insluding the aged material), physical, and environmental conditions both internal and external. $K_{I}$, $\mathrm{K}_{\mathrm{Iscc}}$, and test procedures for determining them are described by program technical documents currently being developed. The 0.7 ratio passing score is similar to ASTM sectjon XI limits. The $K_{I}$ and $K_{I s c c}$ may have to be estimated for the selection process, as the design and fabrication processes will not be finalized.

BJb) Degree of sensitization (austenitic alloys/SCC)

Weighting Factor: 1

Parameter: EPR ratio

Passing score: 5\% maximum

Score: $0 \ldots \ldots 1 \ldots \ldots 2 \ldots \ldots 3 \ldots .44 \ldots 5 \ldots 6 \ldots . \ldots 7 \ldots . \ldots 9 \ldots 10$

Scale: $100 \quad 10$

10.1

Units:

EPR ratio \%

Electrochemical potentiokinetic reactivation (EPR) test. The worst case is likely to be the final closure weld and heat affected zone after long term aging. Passing score is a common screening value for testing austenitic stainless steels.

B3c) Threshold potential (austenitic alloys/TGsCC)

Weighting Factor: 1

Parameter: E(critical) - E(corrosion)

Passing score: 100 millivolts minimum difference

Score: $0 \ldots \ldots 1 \ldots \ldots 2 \ldots . \ldots 3 \ldots 4 \ldots 5 \ldots 6 \ldots \ldots \ldots . \ldots 8 \ldots 9 . \ldots 10$

Units: milivolts

The difference between the critical potential ior TGSCC and the free corrosion potential under the expected metaliurgical and envixonmental conditions. This is a common test for comparative corrosion susceptibility. The passing score is a common safety margin for potential difference. 
B3d) Smooth specimen stress corrosion cracking.

Weighting Factor: 2

Parameter: $\mathrm{K}_{\mathrm{I}} / \mathrm{K}_{\mathrm{Issg}}$ cc

passing score: "Işsfcc

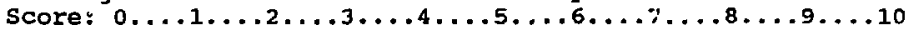

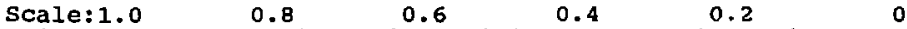

Units: stress intensity/critical stress intensity

This is the ratio of expected stress intensity $\mathrm{K}_{\mathrm{I}}$ (due to residual stresses, applied stresses, and internal flaws), to the

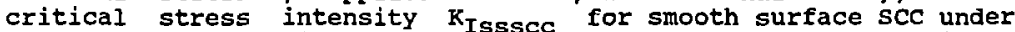
expected metallurgical (including the aged material), physical, and environmental conditions, both internal and external. The 0.7 ratio passing score is similar to ASTM section XI limits. $K_{I}$ and $K_{I s s s c c}$ may have to be estimated for the selection, as final design and fabrication decisions will not be made. $K_{I}$, $\mathrm{K}_{\text {Issscc, }}$ and test procedures for determining them are described by program technical documents currently being developed.

B3e) Likelihood of sufficient concentration of chemical species for corrosion cracking (for example: chloride for austenitic alloys, ammonia or nitrite for copper alloys)

Weighting Facter: 2

Parameter: Likelihood of EAC ion concentrations occurring. Passing score: Adequate/Inadequate confidence cracking wi]: not occur

Score: $0 \ldots \ldots 1 \ldots . \ldots 2 \ldots 3 \ldots .4 \ldots . \ldots 5 \ldots . \ldots 7 \ldots . \ldots . \ldots 9 \ldots 10$

Scale: High Moderate Low

Units: Subjective likelihood

The expected probability that chemical species in the environment which are known to cause or enhance EAC will occur in concentrations sufficient to propagate a crack through the container wall. This includes consideration of topics such as ionic concentrations expected, possible concentrating effects, thermal conditions, and quantity of water present, all as functions of time and for interior and exterior surfaces.

B3f) Likelihood of sufficient hydrogen concentration to cause degradation

Weighting Factor: 1

Parametsr: Likelihood of degrading concentrations of $\mathrm{H}$.

Passing score: Adequate/Inadequate confidence emirittlement will not occur

Score: $0 \ldots \ldots 1 \ldots . \ldots 2 \ldots 3 \ldots \ldots 4 \ldots 5 \ldots 6 \ldots .7 \ldots 8 \ldots .9 . \ldots 10$

Scale: High Moderate Low None

Units: Subjective likelihood

The expected probability that the hydrogen concentration in the' environment will cause sufficient $H$ uptake to cause degradation. This includes consideration of topics such as sources and sinks for hydrogen, radiation fields, surface activators, and the material condition. 
B3g) Hydrogen sensitive phases (for example: martensite or sensitized material for austenitic ailoys, oxide inclusions for copper alloys\}

Weighting Factor: 1

Parameter: Phase fraction

Passing score: 0.01 maximum

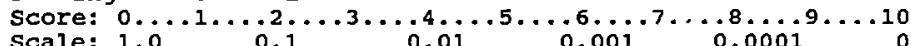

$\begin{array}{lll}\text { Scale: } 1.0 & 0.1 & 0.01 \\ \text { Units: } & & \text { fraction }\end{array}$

Fraction of material composed of phases susceptible to hydrugen cracking, particularly after aging in the finai closure weld and heat affected zone.

B4) Resistance to microbiologically influenced corrosion

Weighting Factor: 5

Parameter: Likelihood of microbiologically influenced corrosion (MIC)

Passing score: Adequate/Inadequate confidence MIC will not occur

Score: $0 \ldots \ldots 1 \ldots .2 \ldots \ldots 3 \ldots \ldots 4 \ldots . \ldots 5 \ldots 6 \ldots \ldots 7 \ldots . \ldots 8 \ldots 9 \ldots 10$

Scale: High Moderate Low INone

Units: Subjective likelihood

The expected probability that microbiologically influenced corrosion of the material will occur in the repository environment at a rate sufficient to cause container failure. Topics to consider include the liklihood of microorganisms living in the repository environment, their possible effects, and the possibility of effective countermeasures.

C) Yredictability of performance

Weighting Factor: 16

c1) Existence of predictive methods to extrapolate degradation phenomena, and methods to extrapolate existing performance data to repository time scales and conditions, or ability to develop such methods.

Weighting Factor: 4

Paraneter: Subjective opinion of "Predictability"

Passing score: Adequate/Inadequate confidence that adequate predictive methods will be available

Score: $\quad 0 \ldots \ldots 1 \ldots \ldots 2 \ldots . \ldots 3 \ldots 4 \ldots . \ldots 5 \ldots 6 \ldots 7 \ldots . \ldots 8 \ldots . \ldots 10$

Scale: None Low Moderate High

Units: $\quad$ Predictability

Estimate of the likelihood that the degradation phenomena can be predicted sufficiently to allow performance assessment. 
Weighting Factor: 4

Parameter: Literature review finding

Passing score: Adequate/Inadequate data available

Score: $\quad 0 \ldots \ldots 1 \ldots . \ldots 2 \ldots 3 \ldots \ldots 4 \ldots 5 \ldots . \ldots \ldots 7 \ldots . \ldots 9 \ldots 10$

Scale:

None

LoW

relative data availability

High

Units:

Long term data include results from years or decades of exposure to known environments from which extrapolation to longer times is" possible if models of the degradation modes exist. Data on materials other than the candidates may be useful if the degradation mode phenomenology is similar enough to be described by the same model.

c3) Ability to generate required data.

Weighting Factor: 4

Parzmeter: Expected ability to generate data

Passing score: Adequate/Inadequate ability to generate data

Score: $\quad 0 \ldots \ldots 1 \ldots \ldots 2 \ldots \ldots 3 \ldots \ldots 4 \ldots \ldots 5 \ldots .6 \ldots 7 \ldots \ldots . \ldots 9 \ldots \ldots 10$

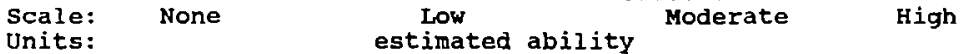

Expected ease or difficulty in producing material performance data required for performance assessment and to support the license application. This is a subjective combination of topics such as: volume and types of data needed, the ease in generating the data, and the uncertainties in the daica due to variables in the material (such as heat-to-heat variations of critical properties).

c4) Relative licensability of the material.

Weighting Factor: 4

Parameter: Relative 1 icensability

Passing score: Adequate/Inadequate licensability

score: $\quad 0 \ldots . \ldots 1 \ldots 2 \ldots . \ldots 3 \ldots 4 \ldots . \ldots 5 \ldots 6 \ldots 7 \ldots . \ldots 8 \ldots . \ldots 10$

Scale: None Low Moderate High

Units: $\quad$ relative licensability

Expected ease or difficulty in demonstratjng sufficient performance predictability to allow licensing. This is a subjective combination of topics such as: development and validation of predictive methods, data availability and validation, prior licensing experience and practice, etc. 
D) Compatibility with other materials

Weighting Factor: 10

D1) Interactions with waste form.

Weighting Factor: 5

Parameter: Subjective opinion of "Compatibility"

Passing score: Adequate/Inadequate compatibility

Score: $\quad 0 \ldots \ldots 1 \ldots \ldots 2 \ldots \ldots 3 \ldots \ldots 4 \ldots \ldots 5 \ldots . \ldots \ldots 7 \ldots \ldots . \ldots 9 \ldots \ldots$

Scale: None Low Moderate High

Units: estimate of compatioility

Whether the container material is likely to interact with the waste forms (spent fuel, cladding, glass waste form, glass pour canister, etc.) in any way which will compromise performance of the waste package. Examples might included: galvanic coupling, formation of aggressive chemical species, interdiffusion effects, etc. This includes products from the container winch affect the waste form as we?I as products from the waste form which affect the container. This criterion may overlap with other issues.

D2) Interactions with the package environment and borehole liner.

Weighting Factor: 5

Parameter: Subjective opinion of "Compatibility"

Passing score: Adequate/Inadequate compatibility

Score: $\quad 0 \ldots \ldots 1 \ldots \ldots 2 \ldots . . \ldots 4 \ldots . \ldots 5 \ldots 6 \ldots \ldots 7 \ldots 8 \ldots . \ldots 9 . \ldots 10$

Scale: None Low Hoderate High

Units: $\quad$ estimate of compatibility

Whether the material is likely to inceract with any features in the nearby emplacement environment (borehole liner, seals, grout, rock, rockbolts, skids, lubricants, etc.) in any way that will compromise performance of the waste package or other repository component. Examples might include: galvanic coupling, formation of aggressive chemical species, interdiffusion effects, ecc. 
E) Fabricability

Weighting Factor: 20

E1) Fabricability of container body.

Weighting Factor: 5

Ela) General formability

Weighting Factor: 2

Parameter: Subjective opinion of formability

Passing score: Adequate/Inadequate formability

Score: $0 \ldots \ldots 1 \ldots \ldots 2 \ldots \ldots 3 \ldots \ldots 4 \ldots . \ldots 5 \ldots 6 \ldots \ldots \ldots . \ldots 8 \ldots 9 \ldots 10$

Scale: None Low Moderate Hich

Units: expected formability

Availability of processes to form container components from the material considering properties such as ductility, microstructure, weldability, etc.

Eib) Product quality

Weighting Factor: 2

Parameter: Subjective opinion of quality

Passing score: Adequate/Inadequate product quality

Score: $0 \ldots \ldots 1 \ldots \ldots 2 \ldots . \ldots 3 \ldots 4 \ldots \ldots 5 \ldots . \ldots 6 \ldots 7 \ldots . \ldots 9 \ldots 10$

Scale: None

Low Moderate

High

Units:

expected quality

Ability to produce reproducible properties such as, composition, microstructure, residual stress, surface finish, etc.

E1c) Inspectability

Weighting Factor: 1

Parameter: Subjective opinion of inspectability passing score: Adequate/Inadequate inspectability

Score: $0 \ldots \ldots 1 \ldots .2 \ldots .3 \ldots 4 \ldots . \ldots 5 \ldots 6 \ldots . \ldots, \ldots 8 \ldots . \ldots 10$

Scale: None

Low

Moderate

High

Units:

expected inspectability

Ability to inspect the fabricated material and document properties such as those discussed in Elb. 
E2) Closeability of container.

Weigiting Factor: 5

E2a) General process considerations

Weighting Factor: 3

Parameter: Subjective opinion of closure processes

Passing score: Adequate/Inadequate closire processes

score: $0 \ldots \ldots 1 \ldots \ldots 2 \ldots \ldots 3 \ldots \ldots 4 \ldots .5 \ldots \ldots 6 \ldots 7 \ldots \ldots 8 \ldots \ldots 9 \ldots . .10$

Scale: None Low Moderate High

Units: expected process quality

Is the material conducive to a high quality final closure in a remote operation? closure studies currently concentrate on welds, but mechanical closure, diffusion bonds and other non-welded closures should be considered. Topics such as process reliability, repairability, safety, filler requirements, and process specifications (such as weld preheat and number of passes etc) should be considered. It may be possible to quantify this criterion by standard tests once the closure process is selected.

E2b) External process influences

Weighting Factor: 2

Parameter: Subjective opinion of external influences

Passing score: Adequate/Inadequate tolerance

Score: $0 \ldots .1 \ldots .2 \ldots .3 \ldots 4 \ldots . \ldots 5 \ldots 6 \ldots 7 \ldots 8 \ldots . \ldots 90$

Scale: None Low Moderate High

Units: expectsil tolerance of external influences

Is the material tolerant of external influences on closure quality, considering topics such as joint cleanliness, alignment, temperature variation, material condition, etc.?

E3) Inspectability of closure.

Weighting Factor: 5

E3a) General process considerations

Weighting Factor: 3

Parameter: Subjective opinion of inspectability

Passing score: Adequate/Inadequate inspectability

Score: $0 \ldots .1 \ldots .2 \ldots .3 \ldots 4 \ldots . \ldots 5 \ldots 6 \ldots . \ldots .6 . \ldots 9 \ldots 10$

Scale: None Low Moderate High

Units: $\quad$ expected inspectability

Does the material lend itself to inspection of the final closure, considering topics such as possible NDE techniques, grain structure, typical flaw NDE signals, etc.? 
E3b) Detectability

Weighting Factor: 2

Parameter: Ratio basis flaw size)

Passing score: 0.5

Passing score: 0.5

Score: $0 \ldots \ldots 1 \ldots . \ldots 2 \ldots 3 \ldots \ldots 4 \ldots 5 \ldots 6 \ldots . \ldots 7 \ldots 8 \ldots \ldots . \ldots 10$

Scale: 2

Units:

1

0.5

size ratic

0.120 .1 .

Are design basis flaws in the container closure large enough to be reliably detected by rapid, remote, NDE techniques?

E4) Damage tolerance of the fabricated and closed container.

Weighting Factor: 5

Parameter: Subjective opinion of damage tolerance

Passing score: Adequate/Inadequate damage tolerance

Score: $\quad 0 \ldots \ldots 1 \ldots .2 \ldots . \ldots 3 \ldots . \ldots 4 \ldots 5 \ldots . \ldots \ldots 7 \ldots . \ldots . \ldots 9 \ldots 10$

Scale: None Low Moderate High

Units:

expected tolerance

Ability of the fabricated and closed container material to tolerate routine handling, emplacement, and possible retrieval activities. 
F) Cost

Weighting Factor: 5

F1) As-fabricated container costs.

Weighting Factor: 2

Parameter: \$ per container

Passing score: NA

Score: $\quad 0 \ldots \ldots 1 \ldots .2 \ldots . \ldots . \ldots 4 \ldots . \ldots 6 \ldots . \ldots 7 \ldots . \ldots 9 \ldots 10$

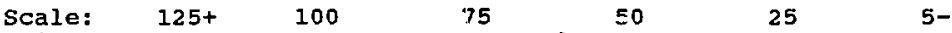

Units: $\mathrm{KS}$

Expected cost of fabricated, closed, and inspected container ready for emplacement. Constant year (1990) dollars.

F2) Associated exceptional repository handling costs.

Weighting Factor: 2

Parameter: Relative added cost

Passing score: Adequate/Inadequate cost

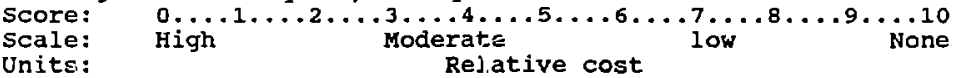

Exceptional repository handling costs specific to the material under consideration relative to other materials. Costs resulting specifically from physical or chemical properties of the container material. Examples might include: handling a heavier waste package made from pure copper which has been made thicker to assure mechanical strength, careful handling of brittle materials, special handing of toxic materials, etc.

F3) Strategic availability of raw material.

Weighting Factor: 1

Parameter: Availability

Passing score: NA

Score: $\quad 0 \ldots \ldots 1 \ldots . \ldots 2 \ldots 3 \ldots \ldots 4 \ldots 5 \ldots \ldots 6 \ldots 7 \ldots . \ldots 8 \ldots 9 \ldots 10$

Scale:

Units:

Low

Moderate

Availabilty

$\mathrm{High}$

Assurance of a long term supply of the raw material needed to fabricate the container. 
G) Previous experience with the material.

Weighting Factor: 5

G1) Previous relevant engineering experience with the material and closure.

Weighting Factor: 3

Gla) Variety of applications

Weighting Factor: 2

Parameter: Variety of applications

Passing score: Adequate/Inadequate applications

Score: $0 \ldots \ldots 1 \ldots . \ldots 2 \ldots 3 \ldots . \ldots 4 \ldots 5 \ldots 5 \ldots \ldots \ldots . \ldots 8 \ldots . \ldots 10$

Scale: None Low Moderate High

Units: $\quad$ Variety of applications

G1b) Years of experience

Heighting Factor: 1

Parameter: Years in service

Passing score: Adequate/Inadequate experience

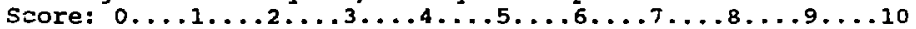

$\begin{array}{llllll}\text { Scale: } 0 & 1 & 10 & 100 & 1000 & 10 \mathrm{~K}\end{array}$

Units: Years

G2) Existing engineering standards for the material and closure.

Weighting Factor: 2

G2a) ASTM Standards

Weighting Factor: 1

Parameter: ASTM coverage

Passing score: Adequate/Inadequate coverage

score: $0 \ldots \ldots 1 \ldots \ldots 2 \ldots \ldots 3 \ldots \ldots 4 \ldots \ldots 5 \ldots \ldots 6 \ldots . \ldots . . \ldots 9 \ldots \ldots 10$

Scale: None Low Moderate High

Units: Extent of ASTM standards

Extent of consideration given the material (or equivalent materials) by ASTM standards.

G2b) Other standards

Weighting Factor: 1

Parameter: Availability of standards

Passing score: Adequate/Inadequate availability

Score: $0 \ldots .1 \ldots 2 \ldots \ldots 3 \ldots . \ldots 4 \ldots 5 \ldots 6 \ldots 7 \ldots 8 \ldots . \ldots 10$

Scale: Ne: $a$ Low Moderate High

Units: Extent of other standards

Availability of standards for application of the material, such as ASME Boiler and Pressure vessel code consideration of the material, or other engineering, construction, or testing standards. 


\section{Appendix A}

This report does not use any information from the Reference Information Base nor contain any candidate information for the Reference Information Base or the Site and Engineering Properties Data Base (SEPDB). 